The reason given by the manufacturers for the alternative sites recommended for children and adults is simply that these were the sites used in the trials of the vaccine (SmithKline Beecham, personal communication). The only indications for administration of hepatitis $B$ vaccine into the upper arm are thus convention and convenience.

Overweight adults generally have a problem with subcutaneous fat on the arms as well as the legs and, although the anterolateral aspect of the thigh may be more severely affected, the number of health service workers in whom this precludes an intramuscular injection is small. The anterolateral aspect of the thigh requires penetration of fascia lata to enter muscle and the feeling of "give" resulting from passage of the needle is a better indicator of the correct site for injection than anything available in the upper arm. It is also easier to differentiate between the buttock and anterolateral aspect of the thigh than between different sites over the deltoid and upper arm.

Work is currently in progress at the Communicable Diseases Surveillance Centre to identify whether any site of injection carries an increased risk of local reaction; the lack of accurate denominator data (numbers of children immunised at different sites) may make this difficult to complete (N Begg, personal communication). Any loss of skin continuity in the upper arm and deltoid region will, however, be more likely to scar badly and will definitely be more obvious than on the anterolateral aspect of the thigh. In an increasingly litiginous population the use of a site where any penetrating injury can result in unsightly scars or keloid formation with no apparent advantage to the patient must be questioned:

All patients should be advised of the alternative sites available for vaccination by intramuscular injection; many will prefer the upper arm but the choice should be theirs.

MARK HENLEY

North East Thames Regional Plastic Surgery Unit,

St Andrews Hospital,

Billericay,

Essex CM12 OBH

1 Payton C. Site of injection for vaccination. BMf 1992;305:364. (8 August.)

\section{Early treatment of meningococcal disease}

EDITOR,-We recently presented data from five health districts on the effect of early treatment with parenteral penicillin on mortality in suspected meningococcal disease..$^{1-3}$ Although in each district there was a lower mortality in those treated early, the reductions in mortality failed to reach significance. As case definitions in the studies were comparable we tested the effect of combining data on the 487 patients from the three published reports.

The overall case fatality was $9 \cdot 7 \%(47 / 487)$. A total of 358 patients did not receive parenteral penicillin before admission, of whom 41 (11.5\%) died; by comparison, six deaths $(4 \cdot 7 \%)$ occurred among the 129 patients who received parenteral penicillin before transfer to hospital. The risk of death in patients not given parenteral penicillin was significantly increased (Mantel-Haenszel weighted odds ratio $2.61 ; 95 \%$ confidence interval 1.04 to $7 \cdot 18)$. These data confirm the benefit of early antibiotic treatment.

The early diagnosis of meningococcal disease may present formidable problems in general practice. Individual doctors will see few cases in their professional lifetime, even in districts with a high incidence. Early symptoms are non-specific, and up to $40 \%$ of patients may not develop a rash in the period before admission to hospital. The diagnosis was, however, suspected in over three quarters of patients seen by a doctor before transfer to hospital in the Darlington study.' We encourage our general practitioner colleagues to carry benzylpenicillin at all times and to give it without hesitation if meningococcal disease is possible.

Public health physicians with special responsibility for communicable disease control can influence rates of giving penicillin. ${ }^{2}$ Departments of public health medicine are well placed to collaborate with microbiologists and hospital physicians to mount information and alerting campaigns directed at local family doctors to sustain awareness of meningococcal disease and to recommend early use of parenteral penicillin. Application of this strategy nationwide could have a considerable impact on the case fatality rate from meningococcal disease.

KEITH CARTWRIGHT

Public Health Laboratory,

Gloucestershire Royal Hospital,

Gloucester GL1 3NN

North Yorkshire Health Project,

JEFFRIE STRANG

York YO3 $4 \mathrm{XF}$

SAVITA GOSSAIN

Department of Microbiology

Worcester Royal Infirmary,

Worcester WR1 3AS

NORMAN BEGG

Public Health Laboratory Service

Communicable Disease Surveillance Centre,

London NW9 5EQ

1 Strang JR, Pugh EJ. Meningococcal infections: reducing the case fatality rate by giving penicillin before admission to hospital. BMF 1992;305:141-3. (18 July.)

2 Cartwright $K$, Reilly $S$, White D, Stuart J. Early treatment with parenteral penicillin in meningococcal disease. BMF 1992;305: 143-7. (18 July.)

3 Gossain S, Constantine CE, Webberley JM. Early parenteral penicillin in meningococcal disease. $B \mathcal{F}^{\mathcal{f}}$ 1992;305:523-4. (29 August.)

EDITOR,-Two recent papers have analysed the relation between antibiotic treatment given before admission to hospital and mortality from meningococcal disease and found a trend with fewer deaths among patients receiving parenteral antibiotics before admission. ${ }^{12}$

We have just made a historical cohort study including all 177 patients who were admitted with meningococcal disease to hospitals in the county of North Jutland, Denmark, between 1 January 1980 and 31 December $1989 .^{3}$ As part of this investigation we analysed the relation between prehospital parenteral antibiotic treatment and death from meningococcal disease.

The standard recommendations of the Danish health authorities regarding prehospital treatment of meningococcal disease are that penicillin $G$ should be given intravenously (or intramuscularly if the intravenous attempt is not immediately successful) when petechiae or other signs of meningococcal sepsis are present, and if the patient shows signs of severe meningitis and the transport time to the nearest hospital is more than half an hour.

When the general practitioner suspected meningitis (in 123 of the 177 patients) the recommendations for immediate antibiotic treatment should have been followed. Of these 123 patients, 98 should have had parenteral antibiotic treatment before admission to hospital. In fact only 25 had treatment according to recommendations.

Of the 98 patients, 10 died: six of the 25 patients who received parenteral antibiotics and four of the 73 patients who did not receive parenteral antibiotics before admission. The higher mortality in the parenteral antibiotic group is statistically significant $(p=0.03$, Fisher's test) with odds ratio of $5.4(95 \%$ confidence interval 1.5 to $19 \cdot 2)$.

Of the 177 patients in the study, a total of 11 died: six of 25 patients receiving parenteral antibiotic before admission and five of 152 not receiving parenteral antibiotics before admission. The difference in mortality is statistically significant with odds ratio of $9 \cdot 3(3 \cdot 1$ to $27 \cdot 9)$

Overall 11 patients died in our study. Ten of 15 patients with disseminated intravascular coagulation died, whereas only one patient died out of 162 without disseminated intravascular coagulation. Using logistic regression analysis on the whole study population we found that only the presence of disseminated intravascular coagulation predicted death with statistical significance $(p<0.001)$ with an odds ratio for death of $170(15$ to 1930).

The high mortality (24\%) among the patients who received prehospital treatment with parenteral antibiotics was probably due to a particularly fulminant infection, easily recognisable at home. Thus, our study shows the opposite tendency to the two British investigations. To further elucidate the role of parenteral prehospital antibiotic treatment it seems necessary to evaluate the severity of the meningococcal disease at the time of decision to give the treatment. We recommend stratified analysis taking this into account in future investigations.

Department of Medicine $\mathrm{V}$

University Hospital of Aarhus,

DK-8000 Aarhus C

Denmark

Department of Internal Medicine,

Randers Hospital,

DK-8900 Randers

HENRIK TOFT SøRENSEN

JENS MøLLER-PETERSEN

HENRIK BYGUM KRARUP HELENA PEDERSEN HELLE HANSEN

Department of Internal Medicine $M$

Aalborg Hospital,

DK-9000 Aalborg

Department of Public Health,

County of North Jutland,

DK-9000 Aalborg

1 Strang JR, Pugh EJ. Meningococcal infections: reducing the case fatality rate by giving penicillin before admission to hospital. BMF 1992;305: 141-3. (18 July.)

2 Cartwright K, Reilly S, White D, Stuart J. Early treatment with parenteral penicillin in meningococcal disease. BMf 1992; 305:143-7.

3 Sørensen HT, Møller-Petersen J, Krarup HB, Pedersen H, Hansen H, Hamburger H. Diagnostic problems with meningococcal disease in general practice. $f$ Clin Epidemio (in press)

4 [The State Serum Institute: meningococcal disease/purulen meningitis.] EpiNyt 1984:week 32. (In Danish.)

\section{Controlling leprosy}

EdIToR,-Christian Lienhardt and P E M Fine do not believe that using multidrug treatment alone will achieve the World Health Assembly's goal of eliminating leprosy as a public health problem by the year 2000.' They do accept, however, that "dramatic falls in the incidence of leprosy (or case detection rates) have been documented [which] began in most countries long before the introduction of multidrug treatment" but attribute this decline to "improving socioeconomic standards" and $B C G$ vaccination. ${ }^{1}$ They ignore completely the effect of dapsone monotherapy in interrupting transmission despite evidence from northern Nigeria, Uganda, India, and central Burma.

In striking contrast, none of the patients in Karimui, New Guinea, originally received any chemotherapy and the incidence of the disease remained constant at 5/1000 from 1964 to $1969{ }^{3} \mathrm{~A}$ BCG vaccine trial started there in 1964; the final results were expressed in incidence per 1000 person years ${ }^{4}$ and the significance of the findings has been missed, In November 1967 chemotherapy was started with acedapsone, a long acting sulphone. ${ }^{3}$ Incidence rates can be calculated in vaccinated and unvaccinated groups from the cumulative totals previously published, ${ }^{45}$ and the considerable decline in unvaccinated groups (figure) must be attributable to chemotherapy. Furthermore, only one new patient in the unvaccinated group ${ }^{45}$ was detected after 1972 with 


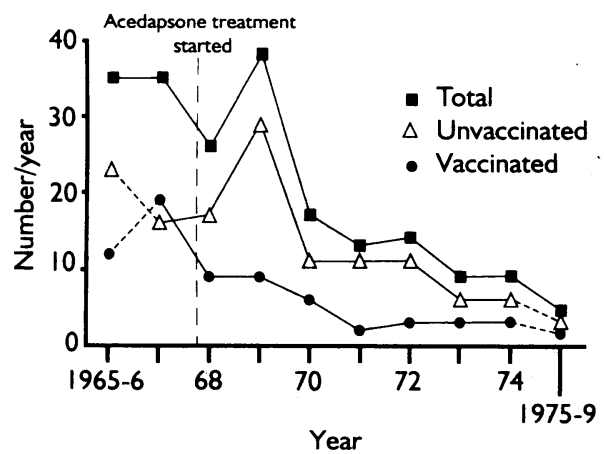

Incidence of leprosy, Karimui, New Guinea. Population was surveyed in 1964 then in 1966, then yearly until 1974. 1965-6 is average of two years. From 1975 to 1979, 19 new cases were detected, six in the vaccinated and 13 in the unvaccinated groups; these have been averaged.

lepromatous, multibacillary leprosy (the reservoir of infection), demonstrating the rapid decline of the disease, previously highly endemic in a very isolated area. Virtually complete interruption of transmission has been achieved 12 years after starting chemotherapy, which cannot be due to "socioeconomic standards."

Surprisingly, Lienhardt and Fine do not consider the findings of the three, double blind, random, controlled trials in Uganda, ${ }^{6}$ New Guinea, ${ }^{4}$ and Burma, ${ }^{7}$ which have given contradictory results, in concluding that BCG is effective in preventing leprosy. Moreover the effect of BCG against lepromatous leprosy, the form which spreads the infection, could not be assessed in the Uganda trial because there were no cases in the unvaccinated group. In the Burma trial $40-70 \%$ of leprosy was predicted to be lepromatous ${ }^{8}$ but only 19 out of 831 patients, or $2.3 \%$ of the unvaccinated group, were found at the final follow up; the reservoir of infection had virtually been removed by dapsone monotherapy, ${ }^{9}$ making assessment of the efficacy of BCG impossible. In Karimui, New Guinea, the effect of BCG against lepromatous leprosy was not statistically significant."

The claim that BCG is effective against leprosy in Venezuela is based on the results of a casecontrol study and not on the randomised, double blind, controlled trial, which compared the effect of BCG alone and BCG with Mycobacterium leprae and did not include an unvaccinated group." The current trial in Malawi also excludes an unvaccinated group..$^{12}$ Finally, in view of the AIDS epidemic, is it safe to carry out routine BCG vaccination? ${ }^{13}$

If leprosy is to be eliminated by 2000 then evaluation needs to be improved. Indeed, it is surprising that a fall in the prevalence of treated cases is being used to monitor the decline of the disease; a fall in incidence should be used. New rates of lepromatous leprosy and leprosy in children should also be recorded. Dapsone monotherapy has been very successful in treating patients and reducing incidence, particularly through the mass treatment campaigns in West Africa; it is unnecessary to give every patient multidrug therapy, which should be reserved for newly diagnosed lepromatous leprosy and for those lepromatous patients who have not responded to dapsone. Most patients with non-lepromatous leprosy have self limiting disease, so they should not need multidrug therapy.

C LCRAWFORD

Department of Anatomy,

Westminster and Charing Cross Hospital,

Westminster and

Lienhardt C, Fine PEM. Controlling leprosy. BM7 1992;305: 206-7. (25 July.)

Crawford CL. In spectacular retreat. BMF 1990;300:261.

3 Boughton CR, Scott GC, Russell DA, Vincin DR. A preliminary report on the use of the depot sulphone preparation acedapsone ("Hansolar") in the control of leprosy. Med F Aust 1971;i: 1258-62

4 Bagshawe A, Scott GC, Russell DA, Wigley SC, Merianos A,
Berry G. BCG vaccination in leprosy: final results of the trial in Karimui, Papua New Guinea, 1963-79. Bull WHO 1989; 67:389-99.

5 Scott GC, Russell DA, Boughton CR, Vincin DR. Untreated leprosy: probability for shifts in Ridley-Joplin classification. Development of "flares: or disappearance of clinically apparent disease. In f L Lepr Other Mycobact Dis 1976;44:110-22

Stanley SJ, Howland $C$ Stone MM, Sutherland I BCO vaccination of children against leprosy: final results. $\mathcal{f} H y g$ vamb 1981;87:233-48.

7 Lwin K, Sundaresan T, Gyi MM, Bechelli LM, Tamondong C, Garbajosa PG, et al. BCG vaccination of children against leprosy: fourteen-year findings of the trial in Burma. Bull leprosy: fourteen-year findings of the

8 Vaccination against leprosy [editorial]. BMf 1966;i:1-2

Lwin K, Zuiderhoek B. Case detection rates for central Burma (1962-1972). Int I Lepr Other Mycobact Dis 1975;43:125-8.

10 Russell DA. BCG vaccination in the prophylaxis of leprosy Abstracts of the 10th International Leprosy Congress, Bergen 1973:135. (No 7/221.)

11 Convit J, Sampson C, Zuniga M, Smith PG, Plata J, Silva J, at al. Immunoprophylactic trial with combined Mycobacterium leprae/BCG vaccine against leprosy: preliminary results. Lancet 1992;339:446-50.

12 Fine PEM, Ponnighaus JM. Leprosy in Malawi. 2. Background, design and prospects of the Karonga prevention trial, a leprosy vaccine trial in northern Malawi. Trans $R$ Soc Trop epros

13 Athale UH, Luo-Mutti C, Chintu C. How safe is BCG vaccination in children born to HIV-positive mothers? Lance 1992;340:434-5.

\section{Removal of central venous catheter and venous air embolism}

EDIToR,- The report from Mennim and colleagues ${ }^{1}$ and the correspondence it has generated ${ }^{23}$ serves as a timely reminder of some of the complications that may occur during the introduction and removal of central venous catheters. The "head down" and Trendelenburg positions are ways of increasing central venous pressure and so prevent the aspiration of air into the venous circulation. Another method that has not been mentioned is to ask patients, while supine, to exhale and hold their breath in expiration. ${ }^{4}$ This increases intrathoracic pressure and causes "flowback" of blood when the syringe is disconnected from the introducing needle. The guide wire is then quickly advanced. If an introducing sheath is placed in the central vein, the pacemaker or pulmonary arterial catheter (for example) may be passed rapidly also during this phase of respiration. For the temporary placement of such catheters, however, the "self seal" type of introducing sheath (with a side arm for flushing) minimises still further the risk of air aspiration. For the occasional patient who is unable to tolerate the head down or Trendelenburg position (because of pulmonary oedema, for example) this is possibly a safer alternative, provided of course that the patient is compliant in performing this sort of manoeuvre. The removal of catheters can also be accompanied by the patient carrying out a similar manoeuvre, the air occlusive dressing being immediately to hand.

Department of Cardiology,

St Bartholomew's Hospital

London EC1A 7BE

1 Mennim P, Coyle CF, Taylor JD. Venous air embolism associated with removal of central venous catheter. BMF 1992;305 171-2. (18 July.)

2 Peters JL. Removal of central venous catheter and venous air embolism. $B M f$ 1992;305:524-5. (29 August.)

3 Baer GA, Nordback I. Removal of central venous catheter and venous air embolism. BMf 1992;305:525. (29 August.)
vers

4 Smith JAR. Minor procedures. In: Kyle J, Smith JAR, Johnston DH, eds. Pye's surgical handicrafi. London: Butterworth Heinemann, 1992:39.

\section{Ecstasy and the dance of death}

EDIToR,-John A Henry states that ecstasy's "psychotherapeutic potential began to be explored in fields as divergent as marriage guidance, alco- holism, and enhancement of perception in elderly people-all without benefit." $\mathrm{He}$ also reports the undesirable physical symptoms reported by me in 1986 but mentions none of the benefits. ${ }^{2}$ This is a misrepresentation of the facts.

Eighteen of my 29 subjects reported positive changes in mood after their session; 23 reported improved attitudes, such as toward self and life in general; 28 reported improvement in interpersonal relationships, and three of the five couples reported benefits from a few days up to two years; nine reported improvements in their working life; 14 reported diminished use of abusable substances (alcohol, marijuana, caffeine, tobacco, cocaine, and LSD); 15 reported beneficial changes in their life goals; and all nine subjects with diagnosable psychiatric disorders reported considerable relief from their problems (dysthymia, simple phobia, personality disorders, and depressive disorders). There were also other benefits during the sessions.

A recent article reports the benefits resulting from the use of the drug by 20 psychiatrists. $^{3}$ Ten reported improved social or interpersonal functioning, nine reported positive changes in values or life priorities, eight reported improved occupational functioning, and five reported a decreased desire to use alcohol, in addition to other benefits.

Henry also states, "While its therapeutic possibilities were being discarded its potential for misuse was being discovered." The therapeutic possibilities are far from being discarded. A group of Swiss psychiatrists have been successfully using the drug as an adjunct to psychotherapy for years, and a psychiatrist at the University of California, Irvine, has applied for permission to study its use in reducing pain and psychological distress in patients with terminal cancer (D Harlow and J Beck, Multidisciplinary Association for Psychedelic Studies international conference of psycholytic psychotherapy, Bern, 1990; C S Grob et al, unpublished data).

I agree that ecstasy can be dangerous in high doses, especially when accompanied by dehydration and increased body temperature from dancing for hours, but in a controlled psychiatric setting it can be beneficial to properly screened and prepared patients. Hopefully, governments in addition to Switzerland's will begin to allow controlled studies to prove conclusively that the benefits experienced by my patients are not the exceptions but the rule.

Santa Fe, New Mexico 87505 , GEORGE GREER

USA

1 Henry JA. Ecstasy and the dance of death. BMF 1992;305:5-6 (4 July.)

2 Greer G, Tolbert R. Subjective reports of the effects of MDMA in a clinical setting. I Psychoactive Drugs 1986;18:319-27.

3 Liester MB, Grob CS, Bravo GL, Walsh RN. Phenomenology and sequelae of 3,4-methylenedioxymethamphetamine use. INerv Ment Dis 1992;180:345-52.

4 Doblin R. Swiss psychedelic research update. Multidisciplinary Association for Psychedelic Studies Newsletter 1992;2:4.

\section{Understanding schizophrenia}

EdITOR,-L S Pilowsky seems to reach a different conclusion from the biological evidence about the nature of schizophrenia ${ }^{1}$ than does Julian Leff in a recent commentary in Nature. ${ }^{2}$ For Pilowsky it is clear that there are structural and physiological abnormalities present in the brain. By contrast, Leff suggests that schizophrenia remains a puzzle and recognises the plethora of hypotheses about the condition.

Some caution may be required when expressing the results of comparisons of the brains of schizophrenic and normal people. For example, although on average the brains of schizophrenic people may have larger ventricles, a simple statement that "schizophrenics have larger ventricles than controls" will be marked wrong in an MCQ examination of the Royal College of Psychiatrists, 